\title{
Sidinei Rocha-de-Oliveira: densidade, ternura e entusiasmo no labor científico
}

\author{
ana Heloísa da Costa Lemos ${ }^{1}$ \\ Aline Mendonça Fraga ${ }^{2}$

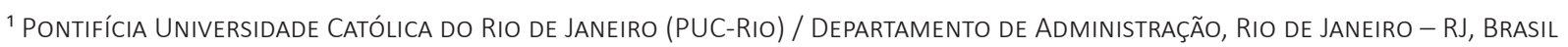 \\ 2 Universidade Federal do Rio Grande do Sul (UFRGS) / Escola de AdMinistração, Porto Alegre - RS, BRASIL
}

"Sid era leve, colorido e brilhante.

De tanto ser, ser o que era, transbordava.

Transbordou tanto que chegou a nós, e nós o temos.

Um pouco de Sid em todas e todos nós."

(Observatório Internacional de Carreiras [OIC], 2021)

UMA BREVE HISTÓRIA DE VIDA DE UMA VIDA BREVE E INTENSA

Sidinei Rocha-de-Oliveira nasceu na cidade de Camaquã, interior do estado do Rio Grande do Sul, em 19 de setembro de 1979. Sua precoce partida, aos 42 anos recém-completados, ocorreu em 3 de outubro de 2021, cerca de um ano após iniciar a luta contra o câncer, na véspera do início do 45 EnAnpad.

Nascido numa região rural, em contexto de agricultura familiar, ainda criança ouvia da avó que um dia seria doutor. Tal imaginário anunciava que sua travessia científica estava traçada; apenas se convertendo em dúvida sobre qual ciência seguir: biológicas, exatas ou humanas. Sid, que veio a se tornar doutor em administração, sabia desde jovem que o melhor caminho para trilhar uma trajetória diferente da sua origem era o estudo.

Sou do Sul, onde os arrozais douram pradarias e o fumo reverdece nos montes. Uma terra em que
política, administração e governo adquirem o sentido e os interesses da agricultura. O "bem-estar
do povo" está na terra, foi o que ouvi dizer. Porém, na prática, acompanhei grandes fazendeiros
revezarem-se na "orientação" dos rumos da cidade, sempre pautando o "bem-estar" da cidade pelo
valor que agregavam às suas terras. Cedo vi que esse não era meu lugar. Um espírito urbano num
meio rural, não tardei a buscar novos caminhos. Partindo de nosso sistema meritocrático, em que
"cada um será recompensado na medida de seu empenho" (não creio), foi o caminho que se apresentou
(Rocha-de-Oliveira \& Ferreira, 2013, p. 492).

Toda a sua formação escolar, do ensino básico ao doutorado, só foi possível pelo ingresso no sistema público. Para cursar a faculdade, precisou emigrar de Camaquã para Porto Alegre. Assim, dizia que iniciara uma vida nômade, buscando romper a barreira de classe e alcançar a mobilidade social almejada. Esse caminho teve como marco o ingresso no curso de administração na Universidade Federal do Rio Grande do Sul (UFRGS), em 1998.

A dedicação e o esforço individual, constantes durante toda a jornada no ensino básico, seguiram mais presentes durante o curso superior. Aos 20 anos, deu início à carreira na pesquisa, como bolsista de iniciação científica da professora Valmiria Carolina Piccinini, que também foi sua orientadora no trabalho de conclusão da graduação e durante todo o percurso de mestrado (2003-2005) e doutorado (2005-2009). Como estudante de graduação, Sid recebeu o primeiro reconhecimento acadêmico: o Prêmio Top Ser Humano da Associação Brasileira de Recursos Humanos (ABRH). Seu doutorado, concluído em 2009, foi cursado em cotutela com a Université Pierre Mendès France, em Grenoble, na França. Sua tese recebeu voto de louvor nacional e internacional.

Sid dizia que, apesar de caber muito bem no discurso da meritocracia, por vir de uma família de classe baixa e alcançar ascensão mediante muito esforço, esse tipo de referência lhe causava um extremo desconforto. "Ninguém deveria passar pelo que passei e viver esse sentimento de vagar entre diferentes mundos sem pertencer a nenhum". Não à toa, carreira, mobilidade social e marcadores sociais de diferença se tornaram seus objetos de estudo e construção acadêmica. Os títulos e 
os status socialmente reconhecidos nunca o afastaram de sua identidade. Além da origem humilde, ele era assumidamente gay, num mundo heteronormativo e violento para quem não está dentro da norma. Contava que a segurança da discrição ou de "não aparentar" suas origens e afetividades vinha acompanhada de muito mais incômodo do que conforto.

O caminho foi sinuoso, mas hoje tenho a tranquilidade de saber que encontrei aquilo que buscava. Da indecisão à certeza: pensei estudar farmácia, estatística ou artes cênicas. Ainda em dúvida, optei por administração. $O$ curso dos indecisos logo se mostrou uma escolha acertada. De estágio a estágio, cheguei logo a um posto de chefia numa grande empresa. Da certeza à indecisão: ter uma equipe, bom salário, perspectiva de carreira e reconhecimento não foram suficientes diante dos choques de valores vivenciados no mundo corporativo. Ainda surpreso com o tratamento quase desumano dado aos estagiários e às práticas eticamente contestáveis, abandonei a grande empresa e comecei o mestrado. Seria professor, para tentar mudar as práticas que sofri e questionei ao vivenciá-las (Rocha-de-Oliveira \& DeLuca, 2017, p. 975).

Conhecido por seu estilo descontraído de vestir, suas nada tradicionais camisetas divertidas e camisas xadrez, usadas para momentos formais, como as bancas, expressavam sua despretensão. Sid falava que era muito curioso ouvir alunas e alunos o chamando de "professor Sid", uma mistura de formalidade com afeto. Mal sabia ele que isso fazia muito sentido para quem teve o privilégio de compartilhar de sua tão trajetória de vida e carreira.

\section{A CONTRIBUIÇÃO PARA OS CAMPOS DE ESTUDOS SOBRE CARREIRAS E INSERÇÃO PROFISSIONAL}

Apesar da curta trajetória acadêmica - a defesa de sua tese de doutorado ocorreu em 2009-, Sidinei Rocha-de-Oliveira trouxe significativas contribuições para a área de administração. Contribuiu, sobretudo, para a literatura de gestão de pessoas e relações de trabalho, com pesquisas sobre mercado de trabalho e inserção profissional e nos estudos de carreiras.

No que tange ao primeiro tema, os múltiplos (des)entendimentos sobre o conceito de mercado de trabalho e a discussão da perspectiva bourdiesiana para compreendê-lo (Rocha-de-Oliveira \& Piccinini, 2011) marcaram seu caminho como pesquisador. A preocupação com as desigualdades e a segmentação na formação e na inserção profissional de jovens foi objeto de estudo de sua tese de doutorado, intitulada Estágios para universitários: representações e implicações na inserção profissional dos jovens brasileiros e franceses (Rocha-de-Oliveira, 2009).

Ao se aprofundar na temática, Sidinei, em parceria com Piccinini, destacou a heterogeneidade que caracteriza as experiências de estágio, associada à diversidade dos perfis socioeconômicos de estudantes. Assim, se, para alguns, o estágio representa a busca por uma experiência profissional relacionada com a área de formação, para outros, o estágio está associado à conquista da independência financeira e ao primeiro contato com o mundo do trabalho. Aspectos contextuais e individuais afetam vivências e expectativas relativas ao estágio. Desse modo, não há uma possibilidade única desse processo, pois "uma diversidade de caminhos se origina a partir da experiência de estágio, tornando ainda mais complexa a compreensão do conceito de inserção profissional” (Rocha-de-Oliveira \& Piccinini, 2012a, p. 44). Como desdobramento desses estudos, Rocha-de-Oliveira e Piccinini (2012b) ressaltaram ainda que, no mercado de trabalho brasileiro contemporâneo, as experiências de estágio se distanciavam de seu caráter formativo e assumiam feições de trabalho precarizado.

O debate sobre a inserção profissional de egressos do ensino superior foi ampliado em estudos posteriores que abordaram a participação em programas de trainee como vivência privilegiada e, portanto, altamente valorizada e disputada de ingresso no mundo corporativo (Bitencourt, Piccinini, Rocha-de-Oliveira \& Gallon, 2014). Já nas pesquisas desenvolvidas em colaboração com Bibiana Volkmer Martins e Camila Scherdien, Sidinei discutiu o desalinhamento entre os programas de expansão do ensino superior e as políticas públicas voltadas à inclusão de jovens profissionais no Brasil. Tal descompasso tende a produzir uma hierarquização entre os cursos, o que coloca em risco a capacidade da formação superior em propiciar igualdade no acesso às vagas disponíveis no mercado de trabalho (Martins \& Rocha-de-Oliveira, 2017a, 2017b; Martins, Scherdien \& Rocha-deOliveira, 2019). 
Em sequência aos estudos acerca da inserção profissional dos egressos dos cursos superiores, Sidinei e Jhony Pereira Moraes discutiram a abordagem de inserção profissional francesa e inglesa, chamada school-to-work. Objetivaram ampliar o debate brasileiro na temática, contemplando as particularidades do país, que englobam as transformações estruturais do ensino superior, o ingresso de diferentes grupos étnicos e econômicos juvenis nesse âmbito de ensino, os limites das condições laborais vigentes e a questão do rebaixamento dos diplomas como consequência da ampliação do número de diplomados (Moraes \& Rocha-de-Oliveira, 2021).

No campo de estudos de carreiras, Sidinei trouxe contribuições teóricas e metodológicas originais, buscando retomar as origens sociológicas e antropológicas, rompendo a dicotomia indivíduo-organização, comum à literatura do campo. Para contribuir para a abordagem interdisciplinar dos estudos de carreira, explorou, com Lisiane Quadrado Closs, o potencial do uso de história de vida para pesquisas sobre trajetórias profissionais, unindo a perspectiva individual com a organizacional e societal (Closs \& Rocha-de-Oliveira, 2015). Em aprofundamento da interdisciplinaridade para o campo, com Gabriela DeLuca e Carolina Dalla Chiesa, propôs um diálogo entre o antropólogo Gilberto Velho e o sociólogo interacionista Everett Hughes (DeLuca, Rocha-de-Oliveira \& Chiesa, 2016). Para dar sequência à proposta, impulsionou lentes pouco exploradas no campo da administração no Brasil, como o interacionismo simbólico e o recurso ao método narrativo, de modo a abordar carreiras tidas como desviantes ou não tradicionais (DeLuca \& Rocha-de-Oliveira, 2016, 2017).

A continuidade da agenda, com Aline Mendonça Fraga, buscou trazer a relevância dos contextos e dos marcadores sociais de diferença, a exemplo de gênero, raça, classe e sexualidade, como centrais nos processos de construção das carreiras (Fraga, Rocha-de-Oliveira \& Gemelli, 2019). Em parceria com outros pesquisadores e pesquisadoras, discutiu sobre a carreira de casais homossexuais e a constituição de uma carreira coletiva (Fraga, Prestes, Rocha-de-Oliveira, Medeiros \& Feijó, 2019). O debate sobre gênero e a questionável neutralidade dos modelos de carreira foram objeto do estudo empírico com mulheres brasileiras expatriadas (Fraga, Antunes \& Rocha-de-Oliveira, 2020). Em produções dos últimos dois anos, os tensionamentos das mobilidades e as potencialidades da perspectiva interseccional (Fraga \& Rocha-de-Oliveira, 2020, 2021), bem como as contribuições da teoria queer para estudar carreiras (Rocha-de-Oliveira \& Fraga, 2020), foram problematizados.

Recentemente, em colaboração com Marcia Cristiane Vaclavik e Andrea Poleto Oltramari, fomentou questionamentos relativos ao cenário emergente da gig economy, trazendo as trajetórias de carreira de motoristas de aplicativos. Em alinhamento com as discussões internacionais e as recentes transformações do mercado de trabalho no Brasil, as características enfatizadas na teoria da carreira proteana, como flexibilidade e adaptabilidade, são colocadas em xeque diante do contexto e do tempo, balizando a agência individual (Vaclavik, Rocha-de-Oliveira \& Oltramari, 2021).

\section{PROFESSOR, PESQUISADOR, ORIENTADOR E COLEGA INESQUECÍVEL}

Sidinei Rocha-de-Oliveira foi um professor, pesquisador, orientador e colega que inspirou muitas trajetórias acadêmicas. Ele era uma mistura de seriedade e ternura, densidade e leveza, cientificidade e fé.

Antes de ingressar como docente na Escola de Administração (EA) da UFRGS, em 2011, foi professor da Universidade Federal Fluminense (UFF), onde orientou 10 trabalhos de conclusão de curso e 2 dissertações de mestrado em pouco mais de um ano de atuação. Como professor da EA, Sid orientou 11 estudantes de iniciação científica, 25 trabalhos de conclusão de curso, 8 dissertações de mestrado, 4 teses de doutorado, além de coorientar 1 tese. Cabe destacar que a tese de Aline Mendonça Fraga, última orientação completa, e a tese coorientada com Andrea Poleto Oltramari, de Marcia Cristiane Vaclavik, foram escolhidas como as melhores do Programa de Pós-Graduação em Administração da EA/UFRGS, nos anos de 2020 e 2021, e indicadas ao Prêmio Capes de Tese.

Como liderança institucional, Sid foi coordenador do Programa de Pós-Graduação em Administração da UFRGS (2019-2021) e vice-presidente do fórum de coordenadores de pós-graduação da UFRGS (2020-2021). Era também coordenador Brasil do Master in International Management, consórcio de 7 instituições de diferentes países - França, Itália, China, México, Brasil, Rússia e Alemanha (2019-2021) -, e representante da EA/UFRGS no Institut Franco-Brésilien d'Administration des Entreprises (2018-2021).

Sid era editor científico da Revista de Administração de Empresas (RAE), editor associado da Brazilian Administration Review (BAR) e avaliador de diversos periódicos nacionais e internacionais. 
Na UFRGS, desenvolveu ações de disseminação de conhecimento por meio do Grupo Interdisciplinar de Estudos da Inovação e do Trabalho (Gineit), fundado em 1995, e, desde 2019, do Observatório Internacional de Carreiras (OIC). Entre 2020 e 2021, integrou, com colegas da universidade, ações de extensão pelos projetos SOS PME e SOS Carreiras - Redes de Assessoria, para auxiliar pequenas e médias empresas e profissionais no enfrentamento da crise gerada pela pandemia da COVID-19.

No âmbito da Anpad, foi membro do Comitê Científico da área de Gestão de Pessoas e Relações de Trabalho, entre 2018 e 2020. Para o EnAnpad 2021, ensaiou seu retorno aos estudos dos sentidos do trabalho, tema de sua dissertação de mestrado, atuando como líder em "Sentidos e significados do trabalho na contemporaneidade: desafios gerais e locais no desenvolvimento do tema".

Quanto às premiações em eventos divisionais da Anpad, Sid recebeu, em 2011, o prêmio de melhor trabalho do terceiro EnGPR, pelo texto "Representações do estágio no Brasil e na França: a perspectiva dos estudantes de administração". Em 2013, no quarto EnGPR, recebeu a indicação ao prêmio de melhor artigo pelo texto "História de vida e trajetórias profissionais: uma proposta interdisciplinar para os estudos de carreira".

Também recebeu duas premiações em EnAnpads, por dois anos consecutivos: o Prêmio de Melhor Trabalho da Divisão de GPR, em 2014, pelo artigo "Contribuições de Gilberto Velho para os estudos sobre carreira: projeto e metamorfose de indivíduos e coletividades", e, em 2015, pelo trabalho "Carreiras com tinta: desenhando uma trajetória profissional no campo da tatuagem".

Neste ano de 2021, recebeu indicação à premiação na Divisão de GPR pelo artigo “Cidades como drivers de carreira: ecossistemas, inovação, sustentabilidade e desenvolvimento nos centros urbanos".

Sua passagem foi tão breve quanto intensa. Deixou como legado contribuições inspiradoras para a pesquisa e o ensino no campo da administração, bem como uma produção de conhecimento que permanecerá viva pelas redes de afeto que construiu com todas as pessoas que tiveram o privilégio de sua companhia.

Diante disso, emerge um questionamento: quantas vidas cruzam o caminho de um professor-pesquisador? Certamente, milhares. Mas quantas vidas se pode, de fato, tocar por meio desse ofício? Isso depende da grandeza, e Sid era gigante. Como medir tal grandeza? De modo objetivo, podemos olhar para a grandeza de Rocha-de Oliveira pela sua produção. Mas, no caso dele, isso não era o mais importante. Para Sid, a melhor medida é o tamanho do seu coração, e não a quantidade de linhas de seu currículo Lattes.

No seu ofício de professor, sempre foi muito generoso e cuidadoso com qualquer discente. Nas aulas, colocava-se numa posição também de aprendiz e exercitava a reflexividade (Rocha-de-Oliveira \& DeLuca, 2017; Rocha-de-Oliveira \& Piccinini, 2009). Ele parecia sempre saber quando era preciso acolher debaixo de suas asas protetoras e quando era o momento de incentivar voos com asas próprias. Como orientador, dialogava, instigava, contribuía. Jamais oprimiu ou diminuiu. Encarava junto os desafios, respeitava, e assim potencializou o melhor de cada orientanda e orientando. Com seu espírito articulador, fez conexões e permitiu contato com uma rede de pesquisadoras e pesquisadores nacionais e internacionais. Em suas andanças acadêmicas, Sid construiu parcerias e amizades sólidas com colegas de diversas universidades. Buscava sempre agregar, inovar e criar pontes. Conquistou respeito e afeto de seus pares na academia.

Tivemos sorte, muita sorte e privilégio, pelo seu toque em nossas vidas. E temos certeza de que ninguém é igual depois disso. Saímos com mais humanidade, mais colaboração, mais resiliência, mais crítica, porém, acima de tudo, com mais disposição para criar laços, amar e construir amor ao nosso redor.

Obrigada, Sid. Que bom saber que estará sempre conosco ao longo da nossa trajetória de carreira, que, como você dizia, é contextual, retrospectiva e projetada, dinâmica e mutável, individual e sempre coletiva! Com todo o nosso carinho, gratidão, admiração e saudades.

\section{AGRADECIMENTOS}

As autoras agradecem a Amanda Ribeiro da Luz, Bibiana Volkmer Martins, Camila Vieira Müller, Catia Eli Gemelli, Laura Alves Scherer, Marcia Cristiane Vaclavik e Vanessa Amaral Prestes pela colaboração na homenagem realizada no EnAnpad 2021, cujos trechos foram incluídos nesta pensata. 


\section{REFERÊNCIAS}

Bitencourt, B. M., Piccinini, V. C., Rocha-de-Oliveira, S., \& Gallon, S. (2014). Programas trainee: entre a inserção qualificante e a seletividade excludente. Revista Economia \& Gestão, 14, 37-30.

Closs, L. Q., \& Rocha-de-Oliveira, S. (2015). História de vida e trajetórias profissionais: estudo com executivos brasileiros. RAC - Revista de Administração Contemporânea, 19, 525-543.

DeLuca, G., Rocha-de-Oliveira, S. (2017). Inked careers: tattooing professional paths. BAR - Brazilian Administration Review, 13, 1-18.

DeLuca, G., Rocha-de-Oliveira, S., \& Chiesa, C. D. (2016). Projeto e metamorfose: contribuições de Gilberto Velho para os estudos sobre carreiras. Revista de Administração Contemporânea, 20, 458-476.

Fraga, A. M., Antunes, E. D., \& Rocha-de-Oliveira, S. (2020). O/A profissional: as interfaces de gênero, carreira e expatriação na construção de trajetórias de mulheres expatriadas. $B B R-$ Brazilian Business Review, 17, 192-210.

Fraga, A. M., Prestes, V., Rocha-de-Oliveira, S., Medeiros, I. B. O., \& Feijó, C. S. (2019). Para além do arco-íris: trajetórias de carreira de casais homossexuais. Revista Psicologia-Organizações e Trabalho, 19, 662-670.

Fraga, A. M., \& Rocha-de-Oliveira, S. (2020) Mobilidades no labirinto: tensionando as fronteiras nas carreiras de mulheres. Cadernos EBAPE.BR, 18(esp), 757-769.

Fraga, A. M., \& Rocha-de-Oliveira, S. (2021). Flight attendant career and social class, gender and sexuality (im)mobilities. Academy of management proceedings. Briarcliff Manor, NY: Academy of Management.

Fraga, A. M., Rocha-de-Oliveira, S., \& Gemelli, C. E. (2019). Cenário das publicações científicas em carreira e gênero. Revista Pensamento Contemporâneo em Administração, 13(3), 158-178.

Martins, B. V., \& Rocha-de-Oliveira, S. (2017a). Expansão e diversificação do ensino superior, impactos no mercado de trabalho e inserção profissional no Brasil: reflexões iniciais e proposta de agenda de pesquisa. Desenvolve - Revista de Gestão do Unilasalle, 6, 53.

Martins, B. V., \& Rocha-de-Oliveira, S. (2017b). Qualificação profissional, mercado de trabalho e mobilidade social: cursos superiores de tecnologia. Sociedade, Contabilidade e Gestão, 12, 21-45.
Martins, B. V., Rocha-de-Oliveira, S., \& Scherdien, C. (2019). Estrutura de classe e mobilidade social no processo de inserção profissional de jovens no Brasil: reflexões e agenda de pesquisa. Cadernos EBAPE.BR, 17(3), 564-576.

Moraes, J. P., \& Rocha-de-Oliveira, S. (2021). Juventude, formação e trabalho: aproximando as teorias de inserção profissional e school-to-work. Educação \& Sociedade, 42, 1-14.

Rocha-de-Oliveira, S. (2009). Estágios para universitários: representações e implicações na inserção profissional dos jovens brasileiros e franceses (Tese de Doutorado). Universidade Federal do Rio Grande do Sul, Porto Alegre, RS.

Rocha-de-Oliveira, S., \& DeLuca, G. (2017). Aprender e ensinar: o dueto do estágio docente. Cadernos EBAPE.BR, 15(4), 974-989.

Rocha-de-Oliveira, S., \& Ferreira, C. S. (2013). Voltando para casa: (re)encontrando Guerreiro Ramos, Tragtenberg e Prestes Motta. Cadernos EBAPE.BR, 11(3), 491-499.

Rocha-de-Oliveira, S., \& Fraga, A. M. (2020). Queering carreiras: interseccionalidades de gênero, sexualidade e classe na trajetória de um bailarino. Cadernos de Gênero e Diversidade, 6, 7-32.

Rocha-de-Oliveira, S., \& Piccinini, V. C. (2009). Validade e reflexividade na pesquisa qualitativa. Cadernos EBAPE.BR, 7(1), 88-98.

Rocha-de-Oliveira, S., \& Piccinini, V. C. (2011). Mercado de trabalho: múltiplos (des)entendimentos. RAP - Revista de Administração Pública, 45(5), 1517-1538.

Rocha-de-Oliveira, S., \& Piccinini, V. C. (2012a). Uma análise sobre a inserção profissional de estudantes de administração no Brasil. RAM - Revista de Administração Mackenzie, 13, 44-75.

Rocha-de-Oliveira, S., \& Piccinini, V. C. (2012b). A construção do mercado de estágios em administração na cidade de Porto Alegre. RPCA - Revista Pensamento Contemporâneo em Administração, 6(4), 29-48.

Vaclavik, M. C., Rocha-de-Oliveira, S., \& Oltramari, A. P. (2021). Proteus looks around: agency, time, and context in a gig economy career analysis. BAR - Brazilian Administration Review, 18, 1-27.

Ana Heloísa da Costa Lemos

ORCID: http://orcid.org/0000-0001-6222-6628

Doutora em Sociologia pelo Instituto Universitário de Pesquisas do Rio de Janeiro (IUPERJ); Professora do Departamento de Administração da Pontifícia Universidade Católica do Rio de Janeiro (PUC-Rio). E-mail: aheloisa@iag.puc-rio.br

Aline Mendonça Fraga

ORCID: https://orcid.org/0000-0002-4240-464X

Doutora em Administração pela Universidade Federal do Rio Grande do Sul (UFRGS); Pesquisadora do Observatório Internacional de Carreiras (OIC/PPGA/UFRGS). E-mail: alinemf.adm@gmail.com 